\title{
Livestock Manure as Potential Reservoir of CTX-M Type Extended-spectrum $\beta$-lactamase Producing Escherichia coli and Klebsiella pneumoniae Associated with Carbapenemase Production
}

\author{
Leimapokpam Sumitra Devi (D), Shobha Broor, Anita Chakravarti and \\ Debasish Chattopadhya* (iD
}

Department of Microbiology, SGT Medical College Hospital and Research Institute, Gurugram, Haryana, India.

\begin{abstract}
Increasing faecal carriage rate of extended-spectrum beta-lactamase (ESBL) producing Escherichia coli (ESBL-EC) and Klebsiella pneumoniae (ESBL-KP) among livestock is responsible for abundance of these bacteria in livestock manure which is being extensively used as organic fertilizer in developing countries including India. Use of this manure can be a potential source for spread of these microorganisms to the human community, posing a serious public health threat especially, to manure handlers. There is paucity of data regarding the possible contamination of environment through use of livestock manure from rural India. Analysis of a total of $\mathbf{1 0 8 0}$ manure sample pools from different segments of $\mathbf{4 0}$ manure heaps each year during the three years period (2015 to 2017) showed a total of 491(45.5\%) $E$. coli and $85(7.9 \%)$ K. pneumoniae to be detected as ESBL producers by double disc synergy test and 3 (0.6\%) ESBL-EC and 3 (3.5\%) ESBL-KP as carbapenemase producers by CarbaNP test. Among the ESBL producers, 436 (88.8\%) ESBL-EC and 59 (69.4\%) ESBL-KP were found to harbour bla ${ }_{\text {CTX-M }}$ genes by PCR. The present study showed an alarmingly high prevalence of ESBL production and emerging evidence of carbapenemase production among $E$. coli and $K$. pneumoniae isolates in the manure samples from rural North India. The antibiotic resistance pattern of the ESBL producing isolates revealed high degree of co-resistance to cephalosporin and non-cephalosporin group of antibiotics.
\end{abstract}

Keywords: ESBL, CTX-M, Carbapenemase, Escherichia coli, Klebsiella pneumoniae, livestock

*Correspondence: dchattopadhya27@gmail.com; 9811256697

(Received: February 06, 2020; accepted: March 06, 2020)

Citation: Leimapokpam Sumitra Devi, Shobha Broor, Anita Chakravarti and Debasish Chattopadhya, Livestock Manure as Potentia Reservoir of CTX-M Type Extended-spectrum $\beta$-lactamase Producing Escherichia coli and Klebsiella pneumoniae Associated with Carbapenemase Production, J. Pure Appl. Microbiol., 2020; 14(1):171-181. https://doi.org/10.22207/JPAM.14.1.18

(C) The Author(s) 2020. Open Access. This article is distributed under the terms of the Creative Commons Attribution 4.0 International License which permits unrestricted use, sharing, distribution, and reproduction in any medium, provided you give appropriate credit to the original author(s) and the source, provide a link to the Creative Commons license, and indicate if changes were made. 


\section{INTRODUCTION}

Faecal carriage of extended-spectrum beta-lactamase (ESBL) producing Escherichia coli (ESBL-EC) and Klebsiella pneumoniae (ESBL-KP) among livestock is being increasingly recognized as a potential source for spread of these microorganisms to the human community, especially in a rural community like India where the livestock share the same residential premises with that of humans ${ }^{1-4}$. Faeces from these animals, in the form of manures, are extensively applied into agricultural fields as organic fertilizer in order to increase the crop yield ${ }^{5}$. Thus, expectedly application of manures has been found to contribute to abundance of ESBL producing enteric bacteria including ESBL-EC and ESBL-KP in agricultural soils ${ }^{4-7}$ contaminating the crops, fruits and vegetables grown ${ }^{8}$ raising possible concern about their contribution to the burden of ESBL mediated resistance in the human community due to unprocessed or inadequately washed vegetables from such soils. This possibility gains further strength from reports on isolation of same genes/plasmids in ESBL-EC strains isolated from humans and livestock ${ }^{3,9,10}$. Out of various molecular types of ESBL, CTX-M type of ESBL, the more recently identified type, has emerged as the most predominant ESBL type replacing the other variants of ESBL'. The present study was carried out to determine the prevalence of CTX-M type ESBL-EC and ESBL-KP in livestock manures used for application in soils and study their antimicrobial resistance patterns over a period of three years.

\section{MATERIALS AND METHODS}

This cross-sectional study was conducted over three years period between August 2015 to September 2017 in the department of Microbiology, SGT Medical College, Hospital and Research Institute, an upcoming tertiary care hospital located in the rural belt of district Haryana, India surrounded by agricultural fields and inhabited by households with agriculture as their main occupation.

\section{Sampling and processing of manure}

Sampling of manure was done each year during the month of August coinciding with the time of application of manure in agricultural fields in the rural districts of Haryana. A total of 40 manure heaps (stored solid manure) prepared from cattle and buffalo faeces of varying degree of freshness were randomly selected in villages surrounding SGT hospital that were stored to be used as organic fertilizer for treatment of agricultural fields. The manure heaps containing dried livestock feces were roughly parabolic in shape with relatively broader base $(4-8 \mathrm{ft})$ compared to top $(2.5-4 \mathrm{ft})$ and with variable heights ( $3.5-5.5 \mathrm{ft}$ ), prepared over 3 to 6 months period. Each manure heap was sub-divided vertically into three equal segments viz. top, middle and base segments based on length of the slope. In each segment, sub-samples were collected in five radial directions from three concentric zones of varying depths i.e. core, midzone and peripheral zone in each segment ${ }^{11}$. The requisite depths of the zones for sampling in each segment was considered as the mid-point of each zone and was calculated from the measurement of the perimeter in the corresponding segment considering each segment as roughly circular (Fig. 1). Collection of dried manure sample was carried out in requisite depths in the order of sampling from periphery to core by gradual removal of the superficial layers of manure heap with gloved hands using separate alcohol treated spades till the requisite depth was reached ${ }^{11}$. The five subsamples from each zone i.e. core, mid-zone and peripheral zone in each segment were pooled. In each segment, zonal samples were pooled to constitute segmental samples. Part of the zonal samples collected from similar zones in three segments were pooled (zonal samples) in three different zip lock plastic bags. The samples were transported in cool boxes containing ice pack and processed within $1 \mathrm{hr}$.

Approximately $0.5 \mathrm{~g}$ of manure sample was suspended in $1.5 \mathrm{ml}$ of nutrient broth and vortexed for 2 mins for homogenization. One hundred microliter of each sample was inoculated on two MacConkey agar plates, one supplemented with $2 \mu \mathrm{g}$ of cefotaxime per $\mathrm{ml}$ (Mac-CTX) and the other supplemented with $2 \mu \mathrm{g}$ of ceftazidime per $\mathrm{ml}$ (Mac-CAZ) ${ }^{12,13}$. The inoculated plates were incubated aerobically at $37^{\circ} \mathrm{C}$ for $24-48 \mathrm{~h}$. Five randomly selected lactose fermenting colonies with identical morphotype suggestive of $E$. coli and $K$. pneumoniae were identified by biochemical test viz. indole, Voges-Proskauer, mannitol motility, Moller's decarboxylase viz. lysine, arginine and ornithine and citrate utilization test ${ }^{14}$ and were 
further validated by Vitek 2 system (BioMerieux, France). These isolates were considered as potential ESBL producers.

Detection of ESBL production and identification of ESBL gene

Detection of ESBL production by Double disc synergy test (DDST)

The potential ESBL producing $E$. coli and $K$. pneumoniae isolates were further confirmed by double disc synergy test, a phenotypic confirmatory test for ESBL detection ${ }^{15}$. Two pairs of antibiotic discs, cefotaxime $(30 \mu \mathrm{g})$, cefotaxime + clavulanic acid $(30 \mu \mathrm{g} / 10 \mu \mathrm{g})$ and ceftazidime $(30 \mu \mathrm{g})$, ceftazidime + clavulanic acid $(30 \mu \mathrm{g} / 10 \mu \mathrm{g})$ were placed on a plate of Mueller Hinton agar (MHA) inoculated with bacterial inoculum matched with 0.5 Mac Farland standard. As per CLSI guidelines, the zone diameter around ceftazidime plus clavulanic acid disc, cefotaxime plus clavulanic acid disc as $\geq 5 \mathrm{~mm}$ larger than that around ceftazidime and cefotaxime discs respectively, was confirmed as ESBL producers. $K$. pneumoniae ATCC 700603 and E. coli ATCC 25922 were used as ESBL positive and negative control strains.

\section{Molecular identification of bla ${ }_{\text {стх-м }}$ gene}

Polymerase chain reaction ( $P C R$ ) for detection of bla $a_{C T X-M}$ was carried out for
ESBL positive strains by DDST using the prepublished sequence, CTX-M primers (CTXMF TTTGCGATGTGCAGTACCAGTAA, CTX-MR CGATATCGTTGGTGGTGCCATA) amplifying 544-bp fragment ${ }^{16}$.

Bacterial DNA was extracted using Wizard Genomic DNA purification kit (Promega, USA). PCR was performed in $25 \mu$ l reaction mixture containing $21 \mu$ l PCR master mix, $0.75 \mu l(300 \mathrm{nmol})$ of each of the two primers and $2.5 \mu$ of the DNA template. Amplification of DNA was performed using Thermal Cycler TC-4000 (Bangalore Genei, India). The cycling conditions were as follows: initial denaturation at $95^{\circ} \mathrm{C}$ for 5 minutes, followed by 30 cycles of denaturation at $95^{\circ} \mathrm{C}$ for $30 \mathrm{~s}$, primer annealing at $51^{\circ} \mathrm{C}$ for $30 \mathrm{~s}$ and primer extension at $72^{\circ} \mathrm{C}$ for $1 \mathrm{~min}$. The time of extension step was increased to $10 \mathrm{~min}$ in the final cycle. For the visualization of PCR products, $10 \mu$ l of PCR product was mixed with $2 \mu$ l of loading dye (a premixed loading buffer containing two different dyes namely bromophenol blue and xylene cyanol FF (Himedia, Mumbai, India) was run on $1 \%$ agarose prepared in Tris-Borate-EDTA buffer containing $0.5 \mu \mathrm{g} / \mathrm{mL}$ of ethidium bromide at $100 \mathrm{~V}$ for $30 \mathrm{~min}$. A 100 bp DNA ladder with range of 100 to 3000 bp (Himedia, Mumbai, India) was included in each gel. The gels were examined in a gel documentation system (Gel Doc EZ Imager, Biorad, USA).

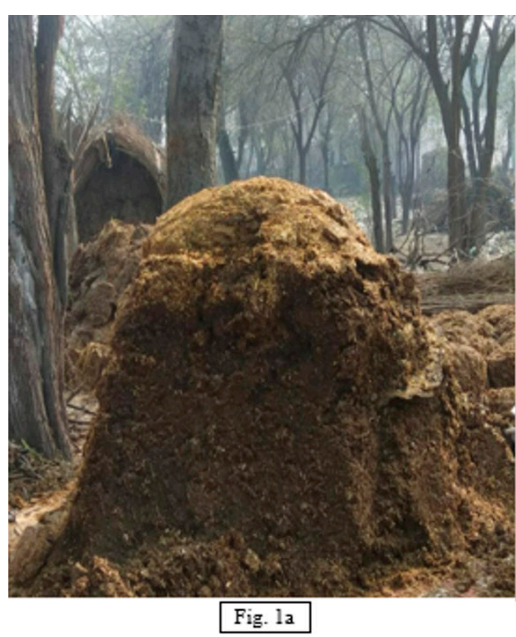

Fig. 1a. Manure heap

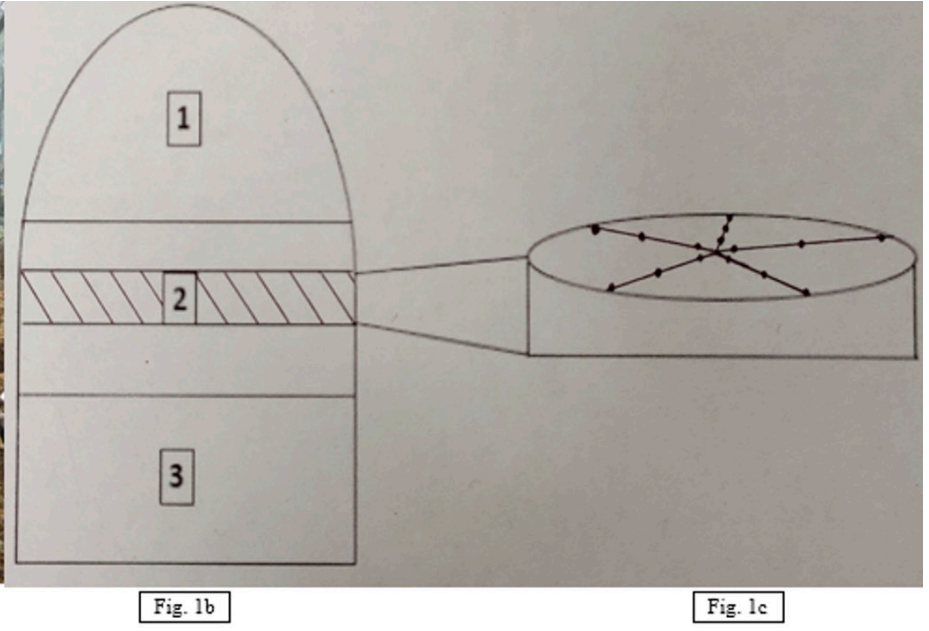

Fig. 1b. Three segments of manure heap $1=$ Top, $2=$ Middle, $3=$ Base
Fig. 1c. Dots represent three radial points (Periphery, mid and core) in each of the five directions of sample collection

Fig 1. Sites of sample collection from manure heap 


\section{Antibiotic susceptibility testing}

All the ESBL-EC and ESBL-KP isolates were subjected to antibiotic susceptibility testing (AST) on Mueller Hinton agar by disc diffusion method. The AST results were interpreted based on zone of inhibition validated as per CLSI guidelines $(2019)^{15}$. Following antibiotics discs procured from Himedia Laboratories, India were tested: ampicillin $(10 \mu \mathrm{g})$, amoxicillin-clavulanic acid $(20 / 10 \mu \mathrm{g})$, piperacillin/tazobactam $(100 / 10 \mu \mathrm{g})$, amikacin $(30 \mu \mathrm{g})$, gentamicin $(10 \mu \mathrm{g})$, cefotaxime $(30 \mu \mathrm{g})$, ceftriaxone $(30 \mu \mathrm{g})$, ceftazidime $(30 \mu \mathrm{g})$, cefepime $(30 \mu \mathrm{g})$, aztreonam $(30 \mu \mathrm{g})$, chloramphenicol $(30 \mu \mathrm{g})$, co-trimoxazole $(25 \mu \mathrm{g})$, ciprofloxacin $(5 \mu \mathrm{g})$, ofloxacin $(5 \mu \mathrm{g})$, ertapenem $(10 \mu \mathrm{g})$, meropenem $(10 \mu \mathrm{g})$ imipenem $(10 \mu \mathrm{g})$, tetracycline $(30 \mu \mathrm{g})$ and tigecycline $(15 \mu \mathrm{g})$. Furthermore, a third-generation cephalosporin viz. ceftiofur known to be used only in veterinary sector, was also included, (EFT disc, $30 \mu \mathrm{g}$, Oxoid Ltd., United Kingdom) and the results were interpreted as per CLSI guidelines for drugs used for veterinary use ${ }^{17}$.

\section{Detection of carbapenemase production among} ESBL-EC and ESBL-KP

Carba NP test was performed for phenotypic confirmation of carbapenemase production among the ESBL-EC and ESBL-KP isolates screened as carbapenemase producers based on resistance to ertapenem and/ or one or more of the other carbapenems in AST as per CLSI guidelines $2019^{15}$.

Table 1. ESBL positivity and CTX-M type of ESBL among E. coli and $K$. pneumoniae isolated from pooled manure samples from various segments of manure heaps

\begin{tabular}{|c|c|c|c|c|c|}
\hline \multirow{2}{*}{$\begin{array}{l}\text { Sampling segments } \\
\text { ( } n=\text { pooled samples } \\
\text { from each zone/segment) }\end{array}$} & \multirow[t]{2}{*}{$\begin{array}{l}\text { Bacterial } \\
\text { isolates }\end{array}$} & \multirow{2}{*}{$\begin{array}{l}\text { Type of } \\
\text { antimicrobial } \\
\text { resistance }\end{array}$} & \multicolumn{3}{|c|}{$\begin{array}{l}\text { Year-wise distribution of resistant } \\
\text { isolates, No. (\%) }\end{array}$} \\
\hline & & & Year 1 & Year 2 & Year 3 \\
\hline & E. coli & ESBL & 35 (29.2) & $67(55.8)^{a}$ & $70(58.3)^{b, c}$ \\
\hline & & CTX-M* & $28(80)$ & $58(86.6)$ & $62(88.6)$ \\
\hline & & $\mathrm{CR}^{*}$ & $0(0)$ & $0(0)$ & $0(0)$ \\
\hline \multirow[t]{5}{*}{ Top $(n=120)$} & K. pneumoniae & ESBL & $8(6.7)$ & $10(8.3)$ & $9(7.5)$ \\
\hline & & CTX-M* & $4(50)$ & $7(70)$ & $7(77.8)$ \\
\hline & & $\mathrm{CR}^{*}$ & $0(0)$ & $0(0)$ & 1 (11.1) \\
\hline & E. coli & ESBL & $54(45)$ & $73(60.8)^{a}$ & $79(65.8)^{b, c}$ \\
\hline & & CTX-M* & $45(83.3)$ & $64(87.7)$ & 72 (91.1) \\
\hline \multirow[t]{6}{*}{ Middle $(n=120)$} & & $\mathrm{CR}^{*}$ & $0(0)$ & $2(2.7)$ & $1(1.7)$ \\
\hline & K. pneumoniae & ESBL & $11(9.2)$ & $17(14.2)$ & $19(15.8)$ \\
\hline & & CTX-M* & $8(72.7)$ & $12(70.6)$ & 15 (78.9) \\
\hline & & $\mathrm{CR}^{*}$ & $0(0)$ & $0(0)$ & $2(10.5)$ \\
\hline & E. coli & ESBL & 23 (19.2) & $41(34.2)$ & $49(40.8)^{c}$ \\
\hline & & CTX-M* & $19(82.6)$ & $35(85.4)$ & $43(87.8)$ \\
\hline \multirow[t]{6}{*}{ Base $(n=120)$} & & $\mathrm{CR}^{*}$ & $0(0)$ & $0(0)$ & $0(0)$ \\
\hline & K. pneumoniae & ESBL & $2(1.7)$ & $2(1.7)$ & $7(5.8)$ \\
\hline & & CTX-M* & $0(0)$ & $1(50)$ & 5 (71.4) \\
\hline & & $\mathrm{CR}^{*}$ & $0(0)$ & $0(0)$ & $0(0)$ \\
\hline & E. coli & ESBL & 112 (31.1) & $181(50.3)^{a}$ & $198(55)^{b}$ \\
\hline & & CTX-M* & $92(82.1)$ & $157(86.7)$ & $187(94.4)$ \\
\hline \multirow[t]{4}{*}{ Total $(n=360)$} & & $\mathrm{CR}^{*}$ & $0(0)$ & $2(1.1)$ & $1(0.5)$ \\
\hline & K. pneumoniae & ESBL & $21(5.8)$ & $29(8.1)$ & 35 (9.7) \\
\hline & & CTX-M* & $12(57.1)$ & $20(69)$ & 27 (77.1) \\
\hline & & $\mathrm{CR}^{*}$ & $0(0)$ & $0(0)$ & $3(8.6)$ \\
\hline
\end{tabular}

ESBL = Extended - spectrum beta-lactamase, $C T X-M=$ Cefotaximase $M, C R=$ Carbapenem resistant

*Calculated as no (\%) of the total ESBL positive isolates

Note:

i) Significant differences $(p=<0.05)$ observed between years of isolation are shown in table

ii) a, b and c indicate comparisons between year 1 vs year 2, year 1 vs year 3 and year 2 vs year 3 respectively

Journal of Pure and Applied Microbiology 
A pair of $1.5 \mathrm{ml}$ microcentrifuge tubes labelled as " $\mathrm{A}$ " and "B", each containing $100 \mu \mathrm{l}$ of lysis buffer (20mM Tris-HCL containing 0.1\% Triton X-100), were inoculated with a loopful of test bacterial colony, and the suspensions were vortexed for $5 \mathrm{~min}$. To the tube " $A$ ", $100 \mu \mathrm{l}$ of solution $\mathrm{A}$ (phenol red $(0.05 \%)$ and $\mathrm{ZnSO}_{4} .7 \mathrm{H}_{2} \mathrm{O}(0.1$ $\mathrm{mmol} / \mathrm{L}, \mathrm{pH}$ adjusted to 7.8 by adding $0.1 \mathrm{~N} \mathrm{NaOH}$ ) was added, and the tube was vortexed. To the tube $B, 100 \mu$ l of solution A plus imipenem $(6 \mathrm{mg} /$ $\mathrm{ml}$ ) was added and then vortexed. The tubes were incubated at $37^{\circ} \mathrm{C}$ for 2 h. K. pneumoniae ATCC BAA 1705 and $E$. coli ATCC 25922 were used as positive and negative control strain respectively. The test was considered positive when tube " $A$ " was red and tube " $B$ " was orange/yellow and when both tubes remained red, the test was interpreted as negative.

\section{Statistical analysis}

The prevalence of ESBL and CTX-M type and antimicrobial resistance were expressed in terms of percentage resistant and were compared by chi square test as categorical variables. $P$-value $<0.05$ was considered to be statistically significant.

\section{RESULTS}

A total of 120 zonal sample pools from 40 manure heaps ( 1 zonal sample pool representing each of the three zones/ segment/ $X 3$ segments/ manure heap X 40 manure heaps) were analysed

Table 2. ESBL positivity and CTX-M type of ESBL among E. coli and $K$. pneumoniae isolated from pooled manure samples from various zones of manure heaps

\begin{tabular}{|c|c|c|c|c|c|}
\hline \multirow{2}{*}{$\begin{array}{l}\text { Sampling zones } \\
\text { ( } n=\text { pooled samples } \\
\text { from identical zones } \\
\text { of } 3 \text { segments }\end{array}$} & \multirow[t]{2}{*}{$\begin{array}{l}\text { Bacterial } \\
\text { isolates }\end{array}$} & \multirow{2}{*}{$\begin{array}{l}\text { Type of } \\
\text { antimicrobial } \\
\text { resistance }\end{array}$} & \multicolumn{3}{|c|}{$\begin{array}{l}\text { Year-wise distribution of resistant } \\
\text { isolates, No. (\%) }\end{array}$} \\
\hline & & & Year 1 & Year 2 & Year 3 \\
\hline \multirow{5}{*}{ Core $(n=120)$} & \multirow[t]{3}{*}{ E. coli } & ESBL & $32(26.7)$ & $63(52.5)^{\mathrm{a}}$ & $71(59.2)^{\mathrm{b}}$ \\
\hline & & CTX-M* & $25(78.1)$ & $54(85.7)$ & $64(90.1)$ \\
\hline & & $\mathrm{CR}^{*}$ & $0(0)$ & $0(0)$ & $0(0)$ \\
\hline & \multirow[t]{3}{*}{ K. pneumoniae } & ESBL & $4(3.3)$ & $8(6.7)$ & $11(9.2)$ \\
\hline & & CTX-M* & $1(25)$ & $5(62.5)$ & $8(72.7)$ \\
\hline \multirow{7}{*}{$\operatorname{Mid}(n=120)$} & & $\mathrm{CR}^{*}$ & $0(0)$ & $0(0)$ & $0(0)$ \\
\hline & \multirow[t]{2}{*}{ E. coli } & ESBL & $64(53.3)$ & $79(65.8)$ & $88(73.3)^{b}$ \\
\hline & & CTX-M* & $54(84.4)$ & $70(88.6)$ & 79 (89.8) \\
\hline & \multirow{4}{*}{ K. pneumoniae } & $\mathrm{CR}^{*}$ & $0(0)$ & $2(2.5)$ & $1(1.1)$ \\
\hline & & ESBL & $14(11.7)$ & $18(15)$ & $18(15)$ \\
\hline & & CTX-M* & $9(64.3)$ & $13(72.2)$ & $14(77.8)$ \\
\hline & & $\mathrm{CR}^{*}$ & $0(0)$ & $0(0)$ & $2(11.1)$ \\
\hline \multirow{5}{*}{ Periphery $(n=120)$} & \multirow[t]{3}{*}{ E. coli } & ESBL & $16(13.3)$ & $39(32.5)^{\mathrm{a}}$ & $39(32.5)$ \\
\hline & & CTX-M* & $13(81.3)$ & $33(84.6)$ & $34(87.2)$ \\
\hline & & $\mathrm{CR}^{*}$ & $0(0)$ & $0(0)$ & $0(0)$ \\
\hline & \multirow[t]{3}{*}{ K. pneumoniae } & ESBL & $3(2.5)$ & $3(2.5)$ & $6(5)$ \\
\hline & & CTX-M* & $2(66.7)$ & $2(66.7)$ & $5(83.3)$ \\
\hline \multirow{7}{*}{ Total $(n=360)$} & & $\mathrm{CR}^{*}$ & $0(0)$ & $0(0)$ & $1(16.7)$ \\
\hline & \multirow[t]{2}{*}{ E. coli } & ESBL & 112 (31.1) & $181(50.3)^{\mathrm{a}}$ & $198(55)^{b}$ \\
\hline & & CTX-M* & $92(82.1)$ & $157(86.7)$ & $177(89.4)$ \\
\hline & \multirow{4}{*}{ K. pneumoniae } & $\mathrm{CR}^{*}$ & $0(0)$ & $2(1.1)$ & $1(0.5)$ \\
\hline & & ESBL & $21(5.8)$ & $29(8.1)$ & $35(9.7)$ \\
\hline & & CTX-M* & $12(57.1)$ & $20(69)$ & $27(77.1)$ \\
\hline & & $\mathrm{CR}^{*}$ & $0(0)$ & $0(0)$ & $3(8.6)$ \\
\hline
\end{tabular}

$\mathrm{ESBL}=$ Extended - spectrum beta-lactamase, $\mathrm{CTX}-\mathrm{M}=$ Cefotaximase $\mathrm{M}, \mathrm{CR}=\mathrm{Carb}$ apenem resistant *Calculated as no (\%) of the total ESBL positive isolates Note:

i) Significant differences $(P=<0.05)$ observed between years of isolation are shown in table

ii) a, b and c indicate comparisons between year 1 vs year 2, year 1 vs year 3 and year 2 vs year 3 respectively 
during each year for three consecutive years (2015 to 2017) totalling to 1080 samples over the three years study period. Out of the total manure samples processed over the three years period, there were 406 samples which yielded ESBL-EC and 85 samples yielded both ESBL-EC and ESBL-KP with the prevalence of ESBL-EC higher i.e. $45.5 \%$ (491/1080) compared to ESBL-KP 7.9\% (85/1080) $(P=<0.001)$. There was an increasing trend in the prevalence of both ESBL-EC and ESBL-KP over the years (Tables 1, 2). Among the three segments of manure heaps, samples collected from middle segment showed maximum prevalence of ESBL producing bacteria and minimum in base segment. Out of the three different zones in the three different segments of manure heaps chosen for sampling, samples from mid zone of all the three segments showed higher prevalence of ESBL-EC and ESBL-KP compared to other two zones i.e. periphery and core regardless of the year of sampling. High proportion of the ESBL positive $E$. coli and $K$. pneumoniae isolates harboured CTX-M variety of ESBL with gradual increase in its prevalence over the years although such increase was not statistically significant (Tables 1, 2). Among the ESBL-EC and ESBL-KP isolates, 0.6\% (3/491) ESBL-EC and 5.9\% (5/85) ESBL-KP were screened as potential carbapenemase producers based on AST pattern. On further confirmation 0.6\% (3/491) ESBL-EC and 3.5\% (3/85) ESBL-KP were confirmed as carbapenemase producers by CarbaNP test (Tables 1, 2).

All the ESBL-EC and ESBL-KP isolated from manure samples were subjected to AST for evaluation of their co-resistance patterns. All the isolates were $100 \%$ resistant to antibiotics viz. ampicillin and cefotaxime as it was expected. Both ESBL-EC and ESBL-KP isolates showed high degree of resistance (81-100\%) against cephalosporin group of antibiotics including ceftiofur, a thirdgeneration cephalosporin used only in veterinary sector. The co-resistance pattern among the ESBL-EC isolates showed significant increase in the resistance rate to gentamicin and cefepime (a fourth generation cephalosporin) over the years $(p<0.05)$. These isolates showed low degree of resistance to amikacin and piperacillin/tazobactam and high degree of resistance to amoxyclav, chloramphenicol and co-trimoxazole. The resistant rates to tetracycline and fluoroquinolones viz. ciprofloxacin and ofloxacin were high with gradual increase in its resistance rate over the years ( $p$ $<0.05)$. Few ESBL-EC strains were resistant to carbapenems. None of the ESBL-EC isolates were

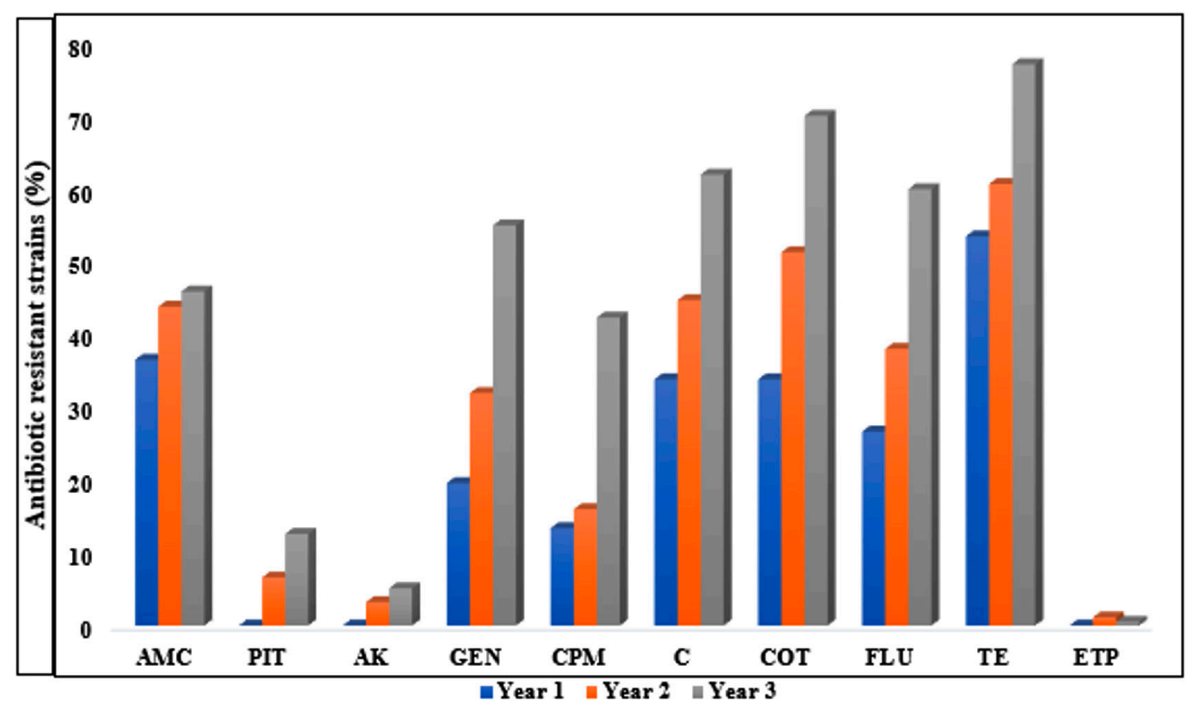

$\mathrm{AMC}=$ Amoxyclav, $\mathrm{PIT}=$ Piperacillin/tazobactam, AK= Amikacin, GEN= Gentamicin, CPM= Cefepime, C= Chloramphenicol, COT= Co-trimoxazole, FLU= Fluoroquinolones, $\mathrm{TE}=$ Tetracycline, ETP = Ertapenem Note: All the isolates were resistant to ampicillin, cefotaxime, aztreonam and were susceptible to tigecycline

Fig. 2. Year-wise antibiotic co-resistance pattern of ESBL producing $E$. coli isolated from manure samples (2015 to 2017) 
resistant to tigecycline (Fig. 2). The co-resistance pattern among the ESBL-KP isolates showed significant increase in the resistance rate for gentamicin over the years. These isolates showed moderate degree of resistance to amikacin and piperacillin/tazobactam and high degree of resistance to amoxyclav, chloramphenicol, co- trimoxazole, tetracycline and fluoroquinolones viz. ciprofloxacin and ofloxacin. Three ESBL-KP strains were resistant to carbapenems and none of them was resistant to tigecycline (Fig. 3). Comparison of co-resistance pattern between ESBL-EC and ESBL-KP showed ESBL-KP to be more resistant to antibiotics tested, with significant

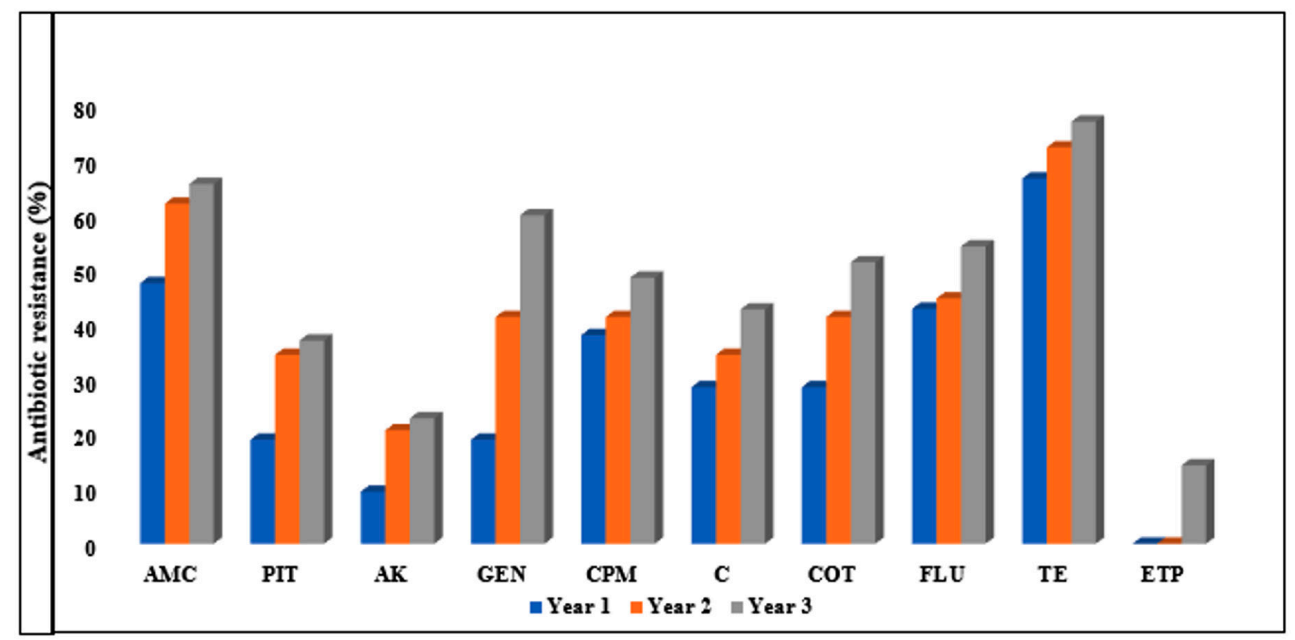

$\mathrm{AMC}=$ Amoxyclav, $\mathrm{PIT}=$ Piperacillin/tazobactam, $\mathrm{AK}=$ Amikacin, GEN= Gentamicin, $\mathrm{CPM}=\mathrm{Cefepime}, \mathrm{C}=$ Chloramphenicol, COT= Co-trimoxazole, FLU= Fluoroquinolones, $\mathrm{TE}=$ Tetracycline, ETP = Ertapenem Note: All the isolates were resistant to ampicillin, cefotaxime, aztreonam and were susceptible to tigecycline Fig. 3. Year-wise antibiotic co-resistance pattern of ESBL producing $K$. pneumoniae isolated from manure samples (2015 to 2017)

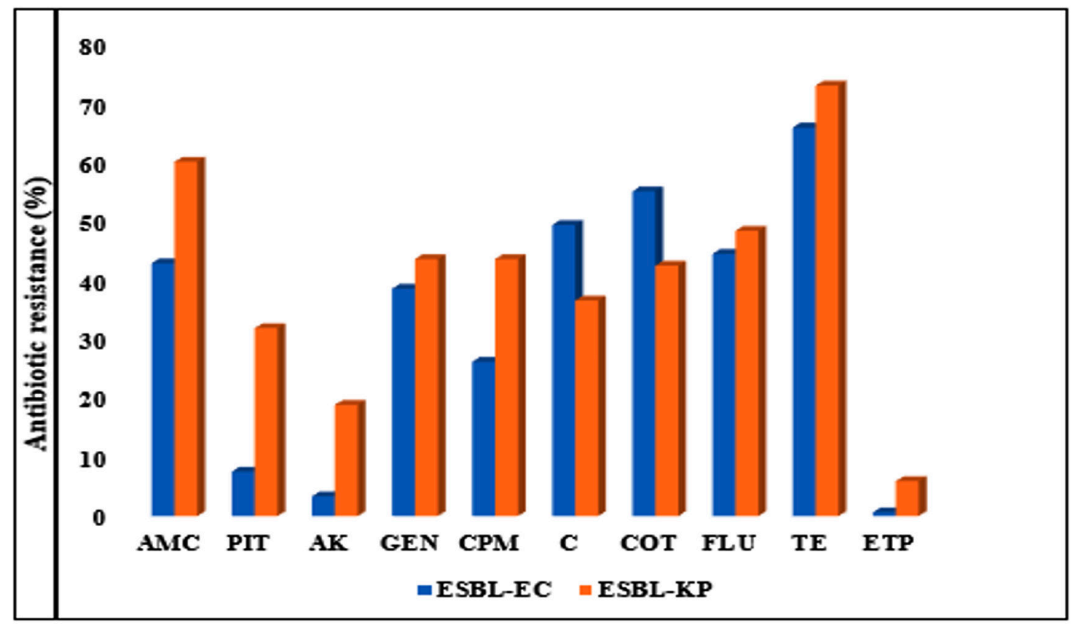

$\mathrm{ESBL}-\mathrm{EC}=\mathrm{ESBL}$ producing $E$. coli, $\mathrm{ESBL}-\mathrm{KP}=\mathrm{ESBL}$ producing $K$. pneumoniae $, \mathrm{AMC}=\mathrm{Amoxyclav}, \mathrm{PIT}=$ Piperacillin/ tazobactam, AK= Amikacin, GEN= Gentamicin, $\mathrm{CPM}=$ Cefepime, $\mathrm{C}=$ Chloramphenicol, $\mathrm{COT}=\mathrm{Co}$-trimoxazole, FLU = Fluoroquinolones, $\mathrm{TE}=$ Tetracycline, $\mathrm{ETP}=$ Ertapenem

Note: All the isolates were resistant to ampicillin, cefotaxime, aztreonam and were susceptible to tigecycline Fig. 4. Comparison of antibiotic co-resistance pattern between ESBL producing $E$. coli and $K$. pneumoniae isolated from manure samples 
difference in the resistance rate to amoxyclav, piperacillin/tazobactam, amikacin, cefepime and chloramphenicol ( $p<0.05)$ (Fig. 4).

\section{DISCUSSION}

Livestock feces in the form of manure has been used as organic fertilizer in the agricultural fields to increase the fertility of soil in both developed as well as developing countries ${ }^{5-7,13}$. This prevalent practice leads to the microbial contamination of agricultural soil with the enteric bacteria carrying antibiotic resistant genes present in the manure generating a potential risk of spreading it to the freshly produced and other environments ${ }^{7,8,12}$. The survival ability of bacterial pathogens in manure can be influenced by the type of manure viz. liquid manure, slurry manure or solid manure ${ }^{18}$.

Admittedly, our approach for collection of solid manure samples was not absolutely free from the risk of minimal mixing of sampling from various depths or zones. Nevertheless, in absence of any standard guidelines, an attempt was made in this regard by adapting a manual and user-friendly approach based on the technique employed by Dang et al. ${ }^{11}$.

In the present study location, application of solid livestock feces manure in agricultural soils are widely practiced, this may likely be a contributor of AMR bacteria or genes in the agricultural soils and its environment as well as transmitter of AMR to manure handlers. The prevalence of ESBL production among $E$. coli and $K$. pneumoniae isolated from solid manure samples were found to be $45.5 \%$ and $7.9 \%$ respectively reflecting alarmingly high fecal carriage rate of such antimicrobial resistance by livestock. Few published studies from developing countries does mention ESBL-EC and ESBL-KP from manure and manure treated soil ${ }^{12,19}$ studies from developing countries viz. Iran and Nigeria reported $43 \%$ and $24 \%$ as prevalence of ESBLEC in bovine manure amended soil and bovine manure respectively ${ }^{5,20}$. However, a study from an agronomy based developing country i.e. China reported higher prevalence of ESBL producing E. coli in manure samples i.e., $72.5 \%^{12}$. Reports on prevalent ESBL producing organisms are not limited to developing countries alone. A study from Germany reported the prevalence of ESBL-
EC in input samples of biogas plants using manure from livestock husbandry as input samples ${ }^{21}$. There is a report on prevalence of ESBL -EC in poultry manure heaps from the Netherlands ${ }^{22}$. However, to the best of knowledge there has not been any report from India in this regard. It has been reported that CTX-M type of ESBL has now become the most predominant ESBL type replacing the other variants of ESBL viz. TEM and SHV ${ }^{9,12}$. This is reflected in the findings of the present study showing the high prevalence of CTX-M type of ESBL detected among ESBL-EC and ESBL$\mathrm{KP}$ isolated from manure samples. This finding is comparable to the prevalence of CTX-M type among ESBL isolates in the manure samples from other countries, viz. China (93.1\%) and Germany $(94 \%)^{12,21}$.

In the present study, the prevalence of AMR bacteria in solid manure sample differed in the subsamples collected from different depths of manure heaps, being maximum in the samples collected from middle segment followed by top segment and base segment. Low prevalence of ESBL producing bacteria in manure at the top segment could be related to the fact that this segment encountered more unfavourable conditions compared to middle and base segments of manure heaps in terms of exposure to sunlight and dry atmosphere leading to decline in viability in bacterial pathogens especially $E$. coli, which is thermolabile ${ }^{18}$. On the other hand, high prevalence of AMR bacteria in the samples collected from middle segment could be due to the moist and warm conditions which is favourable for bacterial growth ${ }^{23}$ while lowest AMR prevalence rate in manure samples collected from base segment could be due to longer storage time of bottom portion of manure heaps affecting the viability of bacteria as fresh livestock feces are placed gradually on top of prior collections in the process of making the manure heaps. A study carried out to determine the fate of E. coli 0157: $\mathrm{H} 7$ in manure heaps reported that the pathogen survived for 42 to 49 days at $37^{\circ} \mathrm{C}$ and for 49 to 56 days at $22^{\circ} \mathrm{C}^{24}$. Furthermore, in each segment, samples from mid zone yielded maximum ESBL-EC and ESBL-KP compared to core and peripheral zones. The manure sample collected from periphery zone of all the three segments were drier than other samples collected from mid and core. Low 
moisture content in these sample could be related with the less isolation rate of ESBL producing bacteria from this zone as enteric bacterial pathogen has been reported to survive for longer period in manure containing high moisture level ${ }^{25}$. Moderate to high degree of multidrug resistance to broad spectrum of antimicrobials exhibited by the ESBL producing isolates in the present study is comparable to studies from Iran, China and Nigeria where ESBL producers isolated from manure samples showed resistance rate ranging from $33.4 \%$ to $100 \%$ for various antimicrobials ${ }^{5,12,20}$. ESBL producing strains showing higher co-resistance to non-cephalosporin group of antibiotics could be due to the transferable ESBL plasmids that also encode resistance genes for other classes of antimicrobials e.g. aminoglycosides, trimethoprim/ sulfamethoxazole ${ }^{26}$. Both ESBL-EC and ESBL$\mathrm{KP}$ isolates showed high degree of resistance against a veterinary antibiotic i.e. ceftiofur, a third generation cephalosporin used primarily in animals, ranging between $86.7-97.5 \%$ and 81-93.1\% respectively reflecting indiscriminate use of this antibiotic in the livestock population in the study area. This finding is comparable to a study from China reporting a high resistance rate i.e., $96.6 \%$ for the same antibiotic in livestock manure ${ }^{12}$. To the best of knowledge, there is paucity of literature on ceftiofur resistance among ESBL producing bacteria isolated from manure sample from India, except one study from Gujarat, India reporting a moderate degree of resistance to ceftiofur (>50\%) among livestock population ${ }^{27}$. India ranked $4^{\text {th }}$ among top countries accounting $3 \%$ of global antimicrobial consumption in livestock ${ }^{28}$. There is no stringent policy on antibiotic use in animal sector in India due to which there is indiscriminate use of antibiotic for veterinary ailments and for growth promotion ${ }^{29}$. In addition to this, some of the factors which encourage development of antimicrobial resistance in a significant way are over-the-counter sale of antibiotics, self-medication, usage of antibiotics without prescription, use of pharmacies and quacks as sources of healthcare ${ }^{29}$. High degree of ceftiofur resistance in livestock could be an indirect risk factor for humans handling manure as this antibiotic has been shown to be capable of horizontal transfer of resistance to other members of third generation cephalosporin group of antibiotics of human therapeutic importance ${ }^{30}$. A case-control study among dairy cattle, treated and untreated with ceftiofur indicated association of high ESBL producing $E$. coli with prior use of ceftiofur ${ }^{30,31}$. Further in-vitro experiment has demonstrated that $E$. coli grown on ceftiofur supplemented medium selects the extended -spectrum cephalosporin resistant $E$. $\mathrm{col}^{32}$. In the present study, limited evidence of carbapenem resistance associated with ESBL production could be demonstrated in $3(0.6 \%)$ and 3 (3.5\%) ESBL-EC and ESBL-KP isolates respectively, that may be viewed as an emerging problem since use of carbapenem in veterinary sector is prohibited globally ${ }^{33}$. To the best of knowledge, there is no study from India so far reporting carbapenem resistance among $E$. coli isolated from animals although studies from other developing countries, viz., Nigeria, China and Iran reported low prevalence of carbapenem resistance among $E$. coli isolated from manure or manure treated soils as $8.2 \%, 3.4 \%$ and $4.8 \%$ respectively $4,5,20$.

\section{CONCLUSION}

The present study highlights the possible spread of ESBL producing bacteria in the rural environment through livestock manure, thus posing as a public health concern for transmission to soil and manure handlers. Limited evidence of carbapenemase production by AMR bacteria in livestock manure, despite pre-existing ban on use of carbapenem in animals further warrants close monitoring of the problem.

\section{ACKNOWLEDGEMENTS}

Authors duly acknowledged the cooperation of farmers in villages for providing access to the manure heaps for sampling.

\section{CONFLICT OF INTEREST}

The authors declare that there is no conflict of interest.

\section{FUNDING}

None.

\section{AUTHORS' CONTRIBUTIONS}

LSD contributed in collection of samples, conducting laboratory work and manuscript writing; DC contributed in designing the protocol 
of the study, carried out analysis of data and contributed in manuscript writing; SB contributed in designing the protocol and manuscript writing; AC supervised the work and undertook revision of the manuscript.

\section{DATA AVAILABILITY}

All the data used in the table and figures are available in excel sheet and can be provided within the limit of ethical guidelines.

\section{ETHICS STATEMENT}

The protocol of the study was approved by both independent institutional research and ethical committees of SGT University (SGTU/ FMHS/MICRO/341).

\section{REFERENCES}

1. Madec JY, Lazizzera C, Chatre P, Meunier D, Martin S, Lepage $\mathrm{G}$, et al. Prevalence of fecal carriage of acquired Expanded-Spectrum Cephalosporin resistance in Enterobacteriaceae strains from cattle in France. Journal of Clinical Microbiology, 2008; 46(4): 15661567. https://doi.org/10.1128/JCM.02299-07

2. Geser N, Stephan R, Kuhnert P, Zbinden R, Kaeppeli U, Cernela N, et al. Fecal carriage of extended-spectrum beta-lactamase-producing Enterobacteriaceae in swine and cattle at slaughter in Switzerland. Journal of Food Protection, 2011; 74(3): 446-449. https://doi. org/10.4315/0362-028X.JFP-10-372

3. Ewers C, Bethe A, Semmler T, Guenther S, Wieler LH. Extended-spectrum beta-lactamase-producing and AmpC-producing Escherichia coli from livestock and companion animals, and their putative impact on public health: a global perspective. Clinical Microbiology and Infection, 2012; 18(7): 646-655. https://doi.org/10.1111/j.1469-0691.2012.03850.x

4. Gao L, Tan Y, Zhang X, Hu J, Miao Z, Wei L, et al. Emissions of Escherichia coli carrying extendedspectrum $\beta$-lactamase resistance from pig farms to the surrounding environment. International Journal of Environmental Research and Public Health, 2015; 12: 4203-4213. https://doi.org/10.3390/ijerph120404203

5. Hosseini A, Azari AA, Danesh A. Prevalence of extendedspectrum $\beta$-lactamase-producing Escherichia coli in agricultural fields of Gorgan district using bovine manure. International Journal of Molecular and Clinical Microbiology, 2016; 6(2): 687-692.

6. Guber AK, Pachepsky YA, Shelton DR, Yu O. Effect of bovine manure on fecal coliform attachment to soil and soil particles of different sizes. Applied and Environmental Microbiology, 2007; 73: 3363-3370. https://doi.org/10.1128/AEM.02434-06

7. Marti R, Scott A, Tien YC, Murray R, Sabourin L, Zhang Y, et al. Impact of manure fertilization on the abundance of antibiotic-resistant bacteria and frequency of detection of antibiotic resistance genes in soil and on vegetables at harvest. Applied and Environmental
Microbiology, 2013; 79: 5701-5709. https://doi. org/10.1128/AEM.01682-13

8. Solomon EB, Yaron S, Matthews KR. Transmission of Escherichia coli 0157:H7 from contaminated manure and irrigation water to lettuce plant tissue and its subsequent internalization. Applied and Environmental Microbiology, 2002; 68: 397-400. https://doi. org/10.1128/AEM.68.1.397-400.2002

9. Founou LL, Founou RC, Allam M, Ismail A, Djoko $C F$, Essack SY. Genome sequencing of extendedspectrum beta-lactamase (ESBL)-producing Klebsiella pneumoniae isolated from pigs and abattoir workers in Cameroon. Frontiers in Microbiology, 2018; 9: 188. https://doi.org/10.3389/fmicb.2018.00188

10. Chapman PA, Siddons CA, Manning J, Cheetham C. An outbreak of infection due to verocytotoxinproducing Escherichia coli $\mathrm{O} 157$ in four families: the influence of laboratory methods on the outcome of the investigation. Epidemiology and Infection, 1997; 119: 245-250. https://doi.org/10.1017/ s0950268897007991

11. Dang STT, Truong DV, Madsen H, Dalsgaard A. Survival of faecal indicator bacteria in treated pig manure stored in clay-covered heaps in Vietnam. Veterinary Microbiology, 2011; 152(3-4): 374-378. https://doi. org/10.1016/j.vetmic.2011.05.004

12. Gao L, Hu J, Zhang X, Wei L, Li S, Miao Z, et al. Application of swine manure on agricultural fields contributes to extended-spectrum beta-lactamase producing Escherichia coli spread in Tai'an, China. Frontiers in Microbiology, 2015; 6: 313. https://doi. org/10.3389/fmicb.2015.00313

13. Valverde A, Coque TM, Sanchez-Moreno MP, Rollan A, Baquero $F$, Canton R. Dramatic increase in prevalence of fecal carriage of extended-spectrum $\beta$-lactamaseproducing Enterobacteriaceae during non-outbreak situations in Spain. Journal of Clinical Microbiology, 2004; 42(10): 4769-4775. https://doi.org/10.1128/ JCM.42.10.4769-4775.2004

14. Crichton PB. Enterobacteriaceae: Escherichia, Klebsiella, Proteus and other genera. In: Collee JG, Fraser AG, Marmon BP, Simmons A, editors. Mackie and McCartney practical medical microbiology, $14^{\text {th }}$ edn. New York: Churchill Livingstone; 1996; 361-381.

15. Clinical Laboratory Standard Institute (CLSI), Performance Standards for Antimicrobial Susceptibility Testing; $29^{\text {th }}$ Informational Supplement. M100-S29, CLSI. 2019. Wayne, Pennsylvania, USA.

16. Sidjabat HE, Paterson DL, Adams-Haduch JM, Ewan L, Pasculle AW, Muto CA, Tian GB, Doi Y. Molecular epidemiology of CTX-M-producing Escherichia coli isolates at a tertiary medical center in Western Pennsylvania. Antimicrobial Agents and Chemotherapy, 2009; 53(11): 4733- 4739. https://doi.org/10.1128/ AAC.00533-09

17. Clinical and Laboratory Standards Institute. Performance standards for antimicrobial disk and dilution susceptibility tests for bacteria isolated from animals. Approved standard. 3rd ed. CLSI document M31-A3. 2007. Wayne, Pennsylvania, USA.

18. Manyi-Loh CE, Mamphweli SN, Meyer EL, Makaka G, Simon M, Okoh Al. An Overview of the Control of 
Bacterial Pathogens in Cattle Manure. International Journal of Environmental Research and Public Health, 2016; 13: 843. https://doi.org/10.3390/ ijerph13090843

19. Taneja N, Sharma M. Antimicrobial resistance in the environment: The Indian scenario. Indian Journal of Medical Research, 2019; 149: 119-128. https://doi. org/10.4103/ijmr.IJMR_331_18

20. Olivia E, Yusuf I, Ahmad S. Detection of extended spectrum beta lactamases (ESBLS) and carbapenemases in Escherichia coli isolated from cow-dungs and poultry droppings. Antimicrobial Resistance and Infection Control, 2015; 4: 142. https://doi.org/10.1186/20472994-4-S1-P142

21. Schauss T, Glaeser SP, Gutschow A, Dott W, Kampfer P. Improved detection of extended-spectrum betalactamase (ESBL) producing Escherichia coli in input and output samples of German biogas plants by a selective pre-enrichment procedure. PLOS ONE, 2015; 10(3): e0119791. https://doi.org/10.1371/journal. pone. 0119791

22. Blaak H, Hamidjaja RA, van Hoek AHAM, Heer LD, Husman AMVR, Schets FM. Detection of ExtendedSpectrum Beta-Lactamase (ESBL)-Producing Escherichia coli on Flies at Poultry Farms. Applied and Environmental Microbiology, 2014; 80(1): 239246. https://doi.org/10.1128/AEM.02616-13

23. Elsas JDV, Semenov AV, Costa R, Trevors JT. Survival of Escherichia coli in the environment: fundamental and public health aspects. The ISME J 2011; 5: 173-183. https://doi.org/10.1038/ismej.2010.80

24. Wang G, Zhao T, Doyle MP. Fate of enterohemorrhagic Escherichia coli 0157:H7 in bovine feces. Applied and Environmental Microbiology, 1996; 62: 2567- 2570. https://doi.org/10.1128/AEM.62.7.2567-2570.1996

25. Cools D, Merckx R, Vlassak K, Verhaegen J. Survival of E. coli and Enterococcus spp. derived from pig slurry in soils of different texture. Applied Soil Ecology, 2001; 17: 53-62. https://doi.org/10.1016/S09291393(00)00133-5

26. Doi Y, Park YS, Rivera JI, Adams-Haduch JM, Hingwe A, Sordillo EM, et al. Community-associated extendedspectrum $\beta$-lactamase-producing Escherichia coli infection in the United States. Clinical Infectious Diseases, 2013: 56(5): 641-648. https://doi. org/10.1093/cid/cis942

27. Arya G, Roy A, Choudhary V, Yadav MM, Joshi CG. Serogroups, atypical biochemical characters, colicinogeny and antibiotic resistance pattern of Shiga toxin-producing Escherichia coli isolated from diarrhoeic calves in Gujarat, India. Zoonoses and Public Health, 2008; 55(2): 89-98. https://doi.org/10.1111/ j.1863-2378.2007.01093.x

28. Van Boeckel TP, Brower, Gilbert M, Grenfell BT, Levin SA, Robinson TP, Teillant A, Laxminarayan R. Global trends in antimicrobial use in food animals. Proceedings of the National Academy of Sciences of the United States of America, 2015: 112(18); 5649 - 5654. https:// doi.org/10.1073/pnas.1503141112

29. Gandra S, Joshi J, Trett A, Lamkang AS, Laxminarayan R. Scoping Report on Antimicrobial Resistance in India. Washington, DC: Center for Disease Dynamics, Economics \& Policy, 2017.

30. Sato T, Okubo T, Usui M, Yokota S-i, Izumiyama S, Tamura Y. Association of Veterinary Third-Generation Cephalosporin Use with the Risk of Emergence of Extended-Spectrum-Cephalosporin Resistance in Escherichia coli from Dairy Cattle in Japan. PLOS ONE, 2014; 9(4): e96101. https://doi.org/10.1371/journal. pone.0096101

31. Chantziaras I, Boyen F, Callens B, Dewulf J. Correlation between veterinary antimicrobial use and antimicrobial resistance in food-producing animals: a report on seven countries. Journal of Antimicrobial Chemotherapy, 2014; 69: 827-834. https://doi.org/10.1093/jac/ dkt443

32. Donaldson SC, Straley BA, Hegde NV, Sawant AA, DebRoy $C$, et al. Molecular epidemiology of ceftiofurresistant Escherichia coli isolates from dairy calves. Applied and Environmental Microbiology, 2006; 72: 3940-3948. https://doi.org/10.1128/AEM.02770-05

33. World Organisation for Animal Health (OIE). OIE list of antimicrobial agents of veterinary medicine 2015. http://www.oie.int/fileadmin/Home/eng/ Our-scientific-expertise/docs/pdf/Eng OIE_ List of antimicrobials_May 2015.pdf. 